\title{
HETEROMORPHISM AND THE EVOLUTION OF DIOECY IN EPIGAEA REPENS
}

\author{
M. D. ROSS \\ Department of Biology, Dalhousie University, Halifax, Nova Scotia
}

Received 11.x.68

\section{InTRODUCTION}

IN a paper on the evolution of outbreeding mechanisms in flowering plants, Crowe (1964) put forward the theory that dioecy in Epigaea repens is derived from a dimorphic incompatibility system. In this species both sexes possess styles, but the stigmas in the males are imperfect. Both sexes are reported to be dimorphic for style length (Gray, 1876). The situation in this plant was considered by Darwin (1889), who suggested that experimental pollinations should be done. The purpose of this note is to show that $E$. repens is not dimorphic for style length, and also to give the results of a number of experimental pollinations.

\section{Materials AND methods}

Some specimens were obtained as cut flowers from dealers in Nova Scotia. Because of the trailing nature of the shrub individual plants were probably represented by more than one specimen. Other specimens were potted up from local wild material. Cut flowers used in experimental pollinations and as controls were kept in a modified Hoagland's solution (Hoagland and Broyer, 1936) containing $1 \mathrm{M} . \mathrm{KNO}_{3}$ (1.5 ml. per litre), lM. $\mathrm{Ca}\left(\mathrm{NO}_{3}\right)_{2},\left(2 \mathrm{ml}\right.$. per litre), $1 \mathrm{M} . \mathrm{MgSO}_{4}$ (1 ml. per litre), $1 \mathrm{M} . \mathrm{KH}_{2} \mathrm{PO}_{4}$ ( $2 \mathrm{ml}$. per litre) and 1 per cent. $\mathrm{Fe} \mathrm{Cl}_{3}$ (1 ml. per litre). The solution was changed weekly.

Plants were classified for flower type according to the ratio corolla-tube length to style length ( $\mathrm{C} / \mathrm{S}$ ratio). This ratio is used in fig. 1 and approximately indicates the stigma height relative to the length of the corolla tube. However, the height of the superior ovary in Epigaea also affects the position of the stigma, so that the ratio corolla-tube length to style length with ovary height $(\mathrm{C} / \mathrm{S}+\mathrm{O}$ ratio $)$ is also given for some flowers in table 1 . This ratio is often the same as or up to $0 \cdot 2$ unit smaller than the $\mathrm{C} / \mathrm{S}$ ratio.

\section{Results AND Discussion}

Fig. 1 (a) shows that there is an approximately normal distribution of style length in Epigaea, with no discontinuity and no bimodality. Corollatube length is similarly distributed (fig. I $(b)$ ), and the distribution of the ratio corolla-tube length to style length is again similar, except for a few outlying results (fig. $1(c)$ ). This lack of discontinuity suggests that the stylar variation is not equivalent to Darwinian dimorphic heterostyly, where short- and long-styled plants form distinct classes, unconnected by intermediates. A similar conclusion was reached for Epigaea by East (1940), who stated that there was " no heterostyly, in the Darwinian sense".

Ocular micrometer measurements of maximum diameters of 100 pollen grains from each of 17 male flowers of varying style lengths failed to yield any gross difference in pollen size. Slight but statistically significant differences 
were found, however, both between flowers of similar and dissimilar style lengths. Such a result tends to confirm the absence of true dimorphic heterostyly, since an obvious pollen-size dimorphism is commonly though not invariably associated with style dimorphism.

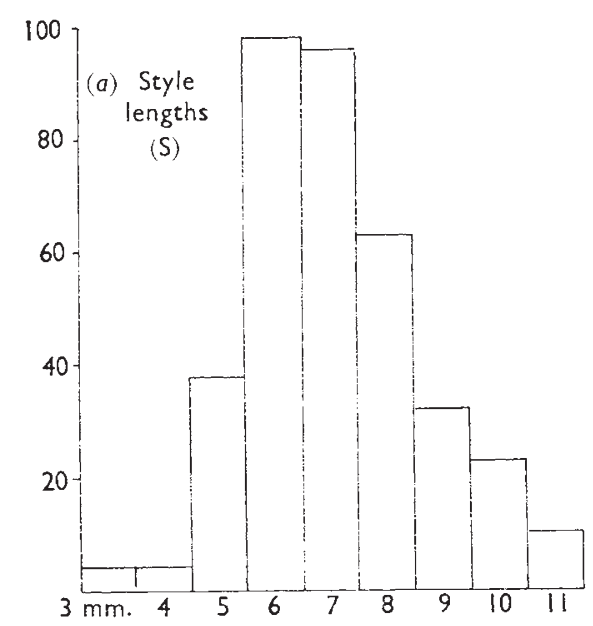

(b) Corolla-tube lengths (C)
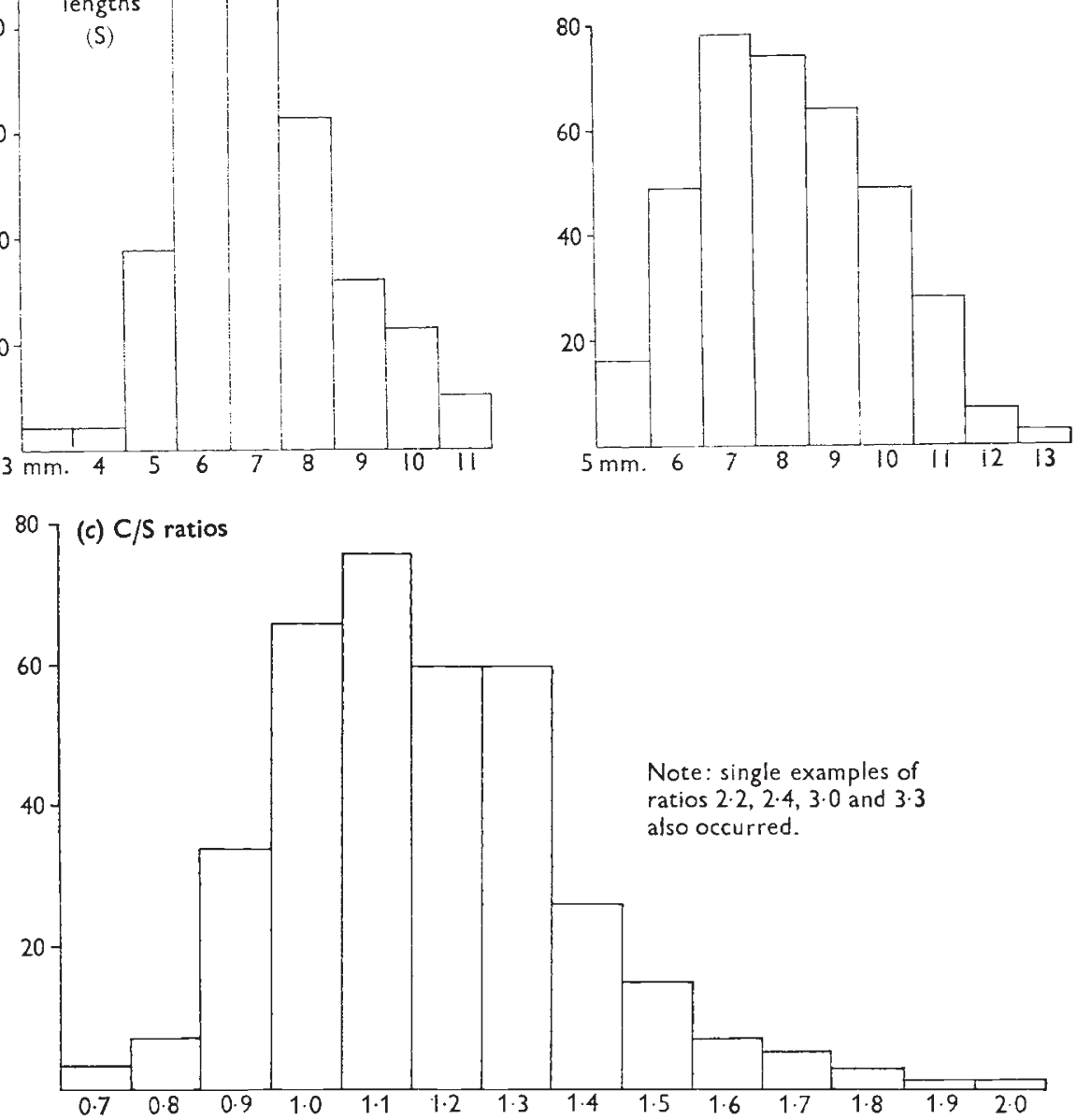

Fig, 1.-Frequencies of $(a)$ style lengths $(b)$ corolla-tube lengths and (c) ratios of corolla-tube to style length $(\mathrm{C} / \mathrm{S})$ in Epigaea repens. These data combine results from several differing populations, and include measurements of both sexes.

Results of experimental pollinations (table 1) show that nearly all crosses appear to be compatible by the criterion of fruit set. Cut flowers set fruit as readily as potted plants, but the fruits remained indehiscent. None of the 15 unpollinated cut flowers which served as controls set a normal fruit, thus incidentally suggesting that lack of pollination is the chief reason why seed capsules are uncommon in nature. A short-styled female (female 1 in table 1) produced capsules, although fruit set on such plants was previously unknown (Crowe, loc. cit.). 


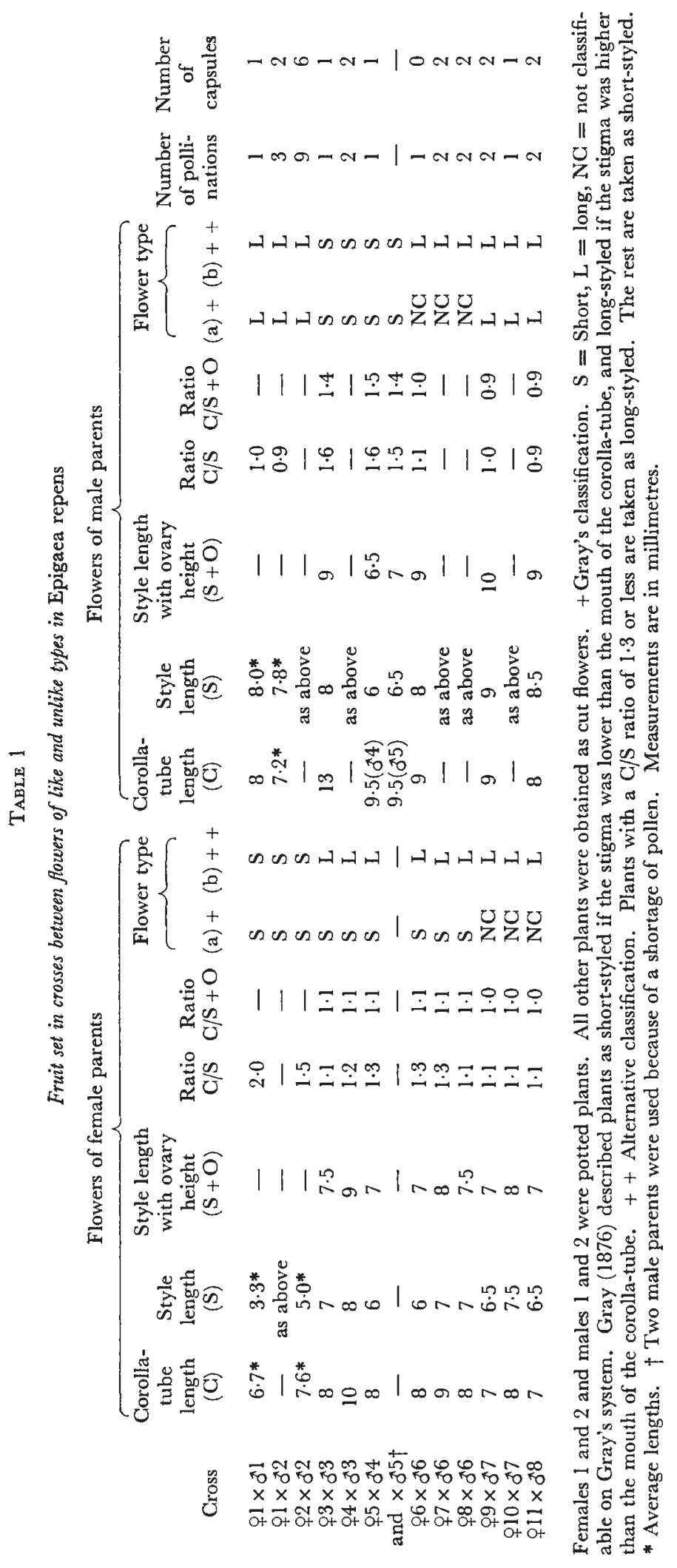


These results do not provide any evidence in support of the theory of Crowe (loc. cit.) that dioecy here evolved from a dimorphic incompatibility system. One might look for evidence connecting the two outbreeding mechanisms in the dioecious Rhamnus catharticus, where Darwin (loc. cit.) found two style lengths in each sex. However, the apparent absence of selfincompatibility in the Rhamnales (East, 1940), and its absence or rarity in the Ericaceae (East, 1940; Fryxell, 1957) suggest that self-compatibility is ancient in both these groups. Furthermore it appears that dioecy is of recent origin in Epigaea. The style and ovary of the male are highly developed, and dioecy is a great rarity in the overwhelmingly hermaphrodite Ericaceae. Thus Meehan (1868) stated that his discovery of dioecy in Epigaea was probably the first instance of this condition in the Ericaceae, while Fryxell (1957) does not record any dioecious member of this family. The Ericales are one of the few orders listed as entirely hermaphrodite by Yampolsky and Yampolsky (1922).

If we accept that self-compatibility in the Ericaceae is ancient, but that dioecy in Epigaea is relatively new, we may suppose that dioecy here evolved recently from hermaphroditism in a self-compatible ancestor.

\section{Summary}

1. The reported occurrence of two style lengths in each sex of the dioecious shrub Epigaea repens has led to the theory that dioecy in this species evolved from a dimorphic incompatibility system. This paper reports an attempt to test this theory.

2. Lengths of styles and corolla tubes were approximately normally distributed with no bimodality.

3. Pollen grains from male flowers of different types were similar in diameter.

4. Fruits were set in crosses between flowers of like type and between flowers of unlike type.

5. Fruits were obtained from females with short styles.

6. The absence of an incompatibility system, the rarity of incompatibility in the Ericales and the absence of style dimorphism do not support the theory under discussion.

Acknowledgments. - I thank my former students Linda Carnell and Marc Goldberg for measuring flowers and pollen. The work was supported by a grant from the National Research Council of Canada.

\section{REFERENGES}

CROWE, L. K. 1964. The evolution of outbreeding in plants. 1. The Angiosperms. Heredity, $19,435-457$.

DARWIN, C. 1889. The Different Forms of Flowers on Plants of the Same Species. D. Appleton and Company, New York.

eAst, Е. m. 1940. The distribution of self-sterility in the flowering plants. Proc. Amer. Phil. Soc., 82, 449-518.

FRYXELL, P. A. 1957. Mode of reproduction of higher plants. Bot. Rev., 23, 135-233.

GRAY, A. 1876. Heteromorphism in Epigaea. Amer. F. Sci., 3, 74-76.

HOAGLAND, D. R., AND BROYER, T. c. 1936. General nature of the process of salt accumulation by roots with description of experimental methods. Plant Physiol., 11, 471-507.

mezhan, т. 1868. Variations in Epigaea repens. Proc. Acad. Nat. Sci. Philadelphia, 153-156. YAMPOLSKY, C., AND YAMPOLSKY, н. 1922. Distribution of sex forms in the Phanerogamic flora. Bibliotheca Genetica, 3, 1-62. 